\title{
Franco Cavallo
}

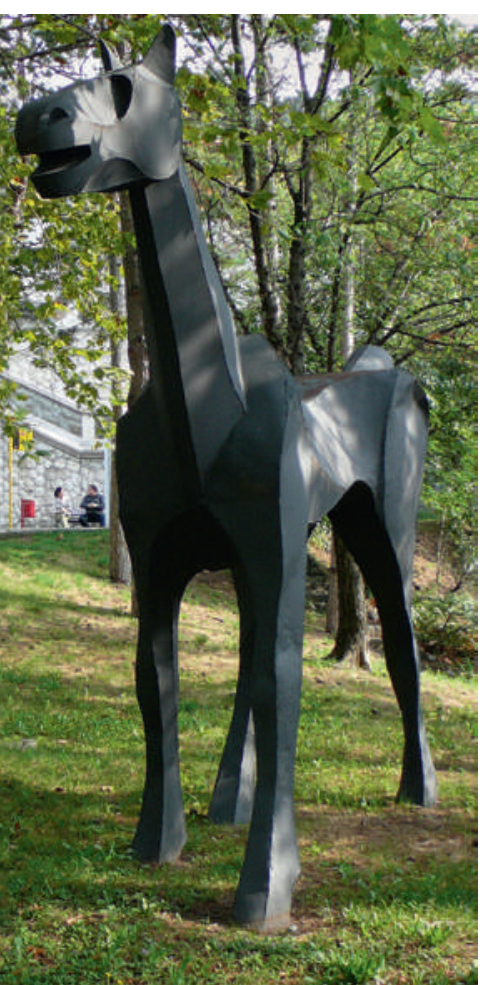

Symbole de la libération: le cheval de l'hôpital avec lequel patients, soignants et médecins parcoururent un jour Trieste en signe de protestation.

Hier, des millions de bulles de savon s'envolaient audessus de la Place de la Bourse comme autant de chatoyants rêves financiers. Aujourd'hui, c'est une mer de drapeaux rouges frappés de la hallebarde triestine qui y ondoie. Les manifestants scandent des slogans contre le gouvernement de Rome, à qui ils reprochent de contrevenir à l'autogestion garantie dans le mémorandum de Londres de 1954. L'organe du «Movimento Trieste Libera» évoque, en italien et en slovène, le passé glorieux du Trieste d'avant la première guerre mondiale. Indépendance politique et autonomie sont supposées attirer des investisseurs pour faire revivre le port délaissé.

Une double page critique la prise en charge des patients psychiatriques: «La diagnosi psichiatrica? La fa il poliziotto.» En 1980, la première accusation entraînait la fermeture d'un hôpital psychiatrique de plus de 1000 occupants, résultat totalement - et mondialement - inédit. Dans le contexte du «compromesso storico» passé entre démocrates-chrétiens et communistes, les choses se mirent à bouger en Italie. Une administration provinciale située plutôt à gauche soutint des expériences et des réformes qui semblaient impensables auparavant. Grâce à Franco Basaglia (1924-1980), l'«asile de fous» municipal de San Giovanni devint dès 1971 un laboratoire social d'où émanèrent de profonds changements. Avant cela, la psychiatrie n'avait plus évolué depuis qu'Ugo Cerletti avait inventé le traitement par électrochocs dans les années 1930. Les fascistes avaient banni la psychanalyse et, avec le soutien d'une médecine universitaire sclérosée, laissé les hôpitaux psychiatriques dégénérer en prisons, que les partisans de Basaglia qualifieraient plus tard de «camps».

Contrairement à ce qui se passa en France, en Angleterre ou aux Etats-Unis, la psychiatrie italienne resta, des décennies durant, plombée par la dictature.

\section{«La mise en œuvre de la <Legge 180〉 entraîna la dissolution progressive de toutes les cliniques psychiatriques publiques.»}

Mais les précurseurs de Basaglia furent nombreux à préparer, puis à soutenir son «movimento anti-istituzionale». Les idées neuves du structuralisme, de la théorie de la communication, de la sociologie et de la linguistique influencèrent une jeune génération de médecins. Leurs modèles s'appelaient Jaspers, Foucault, Sartre, les traducteurs étaient des étudiants, des artistes, des médias. Dans les grands quotidiens, des reportages abordaient régulièrement l'état désolant des établissements psychiatriques. Du «Regards sur la folie» de Mario Ruspoli (1963) au «Vol au-dessus d'un nid de coucou» de Milos Forman (1975), le cinéma dénonça abondamment le système inhumain des hôpitaux fermés. Des années de travail d'information allaient avoir d'importantes conséquences juridiques et médicales.

Aujourd'hui, les bus $n^{\circ} 4$ et 6 mènent au vaste Parc de San Giovanni en empruntant les très passantes rues Battisti et Giulia. Hormis le porche d'entrée, plus un mur n'est visible. Des massifs d'arbres touffus cachent les nombreux pavillons, dont la plupart hébergent désormais des instituts universitaires. Rénovés, certains des bâtiments de l'ère monarchique abritent des services ambulatoires. Tout est calme en ce samedi matin d'automne. Des oiseaux chantent, des séniors discutent dans un jardin ouvrier, de jeunes mères poussent des poussettes, des drogués font une pause cigarette. Devant le bâtiment de la direction se dresse la statue en bronze du fameux Marco Cavallo. Un collectif de patients et d'artistes avait pris pour modèle le cheval qui transportait chaque jour le linge de l'hôpital: faite à l'origine de papier mâché peint en bleu, cette figure est devenue le symbole de la libération le jour où une procession de patients, de soignants et de médecins parcourut le quartier et la ville derrière elle. En Italie, la «Legge 180» éleva la réforme de 1978 au statut de loi dont, en 2001, l'OMS conseillerait au monde entier de s'inspirer. Sa mise en œuvre entraîna la dissolution progressive de toutes les cliniques psychiatriques publiques. Depuis, de nombreux concepts de la psychiatrie sociale sont associés au mouvement radical de l'antipsychiatrie, né à Trieste. S'ils appartiennent désormais au passé, les questions de la folie et de la normalité restent, elles, d'actualité. Surtout à Trieste, ville-frontière, où le monument à la Risiera rappelle le seul camp d'extermination ayant existé sur le sol italien.

Une chorale couvre le bruit de la circulation. Un mégaphone lance «Sveglia Trieste!», tandis que sur la Piazza dell'Unità toute proche, des haut-parleurs encouragent des équipes de baseball, et qu'à la tête d'une procession marchant vers le port et le Molo Audace, un orphéon entonne un Ave Maria. «Trieste, éveilletoi!» est un appel collectif représentatif, hier comme aujourd'hui. Il flotte dans l'air comme un parfum de renouveau.

\section{Erhard Taverna}

Babini VP. Liberi Tutti - Manicomi e Psichiatri in Italia Bologna: Società editrice Mulino; 2009.

Trieste Libera. Giornale d'Informazione del Movimento Trieste Libera. Luglio 2013.

Trieste Libera. Luglio 2013. 